July 1994

\title{
Risk Perception, Communication, and Community Relations
}

Donald G. MacGregor

Decision Research

1201 Oak Street

Eugene, Oregon 97401-3575

Decision Research Report No. 94-11

Prepared for Institute for Water Resources, U.S. Army Corps of Engineers, Workshop on Applied Risk Communication, Vanderbilt Institute for Public Policy Studies, Nashville, Tennessee 


\section{Risk Perception, Communication, and Community Relations}

Over the past two decades one of the most dramatic phenomenon on the social scene has been the rise of broad, public involvement in decision making about complex technologies, including those that protect society from natural hazards such as floods. Spawned by national legislation that required proponents to assess the environmental impacts of their proposed projects, public involvement in regulation of technology, including siting decisions, has become a pandemic feature of modern risk management.

As a consequence, the public has greater opportunity than ever before to be aware of both risk managers and the workings of their institutions, largely through increased media scrutiny of technology and its failures (e.g., Singer \& Endreny, 1993). Thus, to be a successful risk manager, or risk management institution, is to understand the issues that the public deems important and the mechanisms by which public participation in risk management, including decisions about technologies, can be undertaken in a productive and (relatively) uncontentious manner. To do otherwise is to invite disaster in the form of immense social costs associated with projects that have failed because the public will not provide its support via its role as political constituency or host community.

Arguably, the most salient example of a catastrophic failure of risk management is embodied in the effort to establish a permanent repository site for high-level nuclear waste in the United States at Yucca Mountain, Nevada. Though experts strongly agree that the technical problems can be resolved and the risks effectively managed, the process has become stalled, embroiled in a political controversy fueled by public discontent over the impacts such a project would have on the social and economic future of their state. The post mortem on the U.S. Department of Energy's proposal for Yucca Mountain reveals a stark and disastrous disregard on behalf of the project's proponents for the sentiments of the public who would be impacted by the project, leading to a stalemate in which public distrust overshadows expert proclamations about the proposed repository's safety (Flynn, Kasperson, Kunreuther, \& Slovic, 1992). Though the problems at Yucca Mountain may have received such widespread attention because of the sheer enormity of the project itself, they also reflect a general set of difficulties faced by virtually all proponents of projects that, in one way or another, require the analysis, communication, and management of risks to which the public is exposed. 
Public empowerment in risk management decisions poses strong challenges to risk communication for several reasons. First, the technical issues inherent in risk analysis and assessment are well beyond the grasp of most members of the public. Inherently couched in quantitative language, risk as conceptualized by the technical community bears relatively little resemblance to the conceptualization of risk that is held by lay people.

Second, the questions that risk analysis and assessment seeks to answer are often very different from those for which the public seeks answers. For example, while risk analysis provides answers about the distribution of probabilities associated with a given consequence, the public typically wants to know whether or not they are safe.

Third, the fact of public involvement presupposes that the public wants to be involved and will be a willing party in risk management decisions. Though there is a great deal of evidence that some members of the public hold strong opinions about technological issues and want to exert an influence on risk management decisions, other members of the public may simply prefer to trust that experts will "handle things" so that they can turn their attention to those concerns that are more central to their lives and that dominate their daily worries (MacGregor, 1991). Disputes between project proponents and community activists, or between risk analysts over technical issues, can signal people that trusting experts (or their institutions) may be an imprudent thing to do, thereby causing them to redirect their attention and concern to a project or issue that would otherwise have gone unnoticed. The "enlightened" project proponent, therefore, needs to be aware of how public values about technology are framed, their perceptions of institutional credibility and trust, the agendas of differing "publics" that motivate their participation in risk debates, and the uncertainties that surround the effectiveness of different participation processes (Kasperson, 1986).

Given the importance of the public in decisions about large-scale technological projects, maintaining a strong and cooperative relationship between risk experts and the public at large is of tremendous value. An important tenet of risk management is that the relationship between risk experts and the public at large is well served by taking steps to ensure that the communication of technical risk is 
done to the highest standards of quality. To that end, a wealth of research in risk communication has served as a basis for guidelines that can be followed by project proponents to ensure that the process and content of risk communication meets certain benchmarks, adherence to which offers, by definition, the best hope that conflicts and disagreements will be avoided, or at least minimized. Very little of this basic advice has changed over the years, and excellent overviews of techniques and issues can be found in the following sources (see reference section for complete citations):

- Covello, von Winterfeldt, \& Slovic (1986)

- Covello, Sandman, \& Slovic (1988)

- National Research Council (1989)

What has changed is the emphasis on the need of project proponents and the technical analysis professions to understand the broader social and psychological context within which they and their projects are evaluated by members of the public. The goal of this paper is to present an overview of that context from the perspective of informing the use of risk communication, including what risk communication can reasonably be expected to accomplish in terms of facilitating decisions about project development that include members of the public.

Two Perspectives on Risk Communication
We begin by contrasting two viewpoints about risk communication. The first viewpoint casts risk communication as a matter of form and content. Its essential goals are to provide technical information about risks, in an understandable form, with the purpose of achieving public reassurance and confidence in the risk management process. In many cases, there is an unstated intention to convince the public that risks are small, or smaller than they are perceived to be. This is very much an expert viewpoint on the mission of risk communication, with heavy emphasis on the technical content of risk messages. To its credit, it seeks to involve the public in an ostensibly open and two-way dialogue about risk, and strongly encourages risk communicators to be sensitive to public concerns. However, its tenor is predominantly educational, and its prescription for openness generally does not extend to empowering the public in risk management decisions. Thus, risk communication of this type can do little to change public participation in the risk management process, and, therefore, virtually nothing to 
modify the power and control imbalance that exists between the technical community and the public at large.

In the second viewpoint, risk communication is part of the process of managing risks. Most, if not all, of the form and content prescribed for good risk communication are what the public typically expects would be done in a normal and appropriate process for managing anything in society. Thus, risk communication practiced to its highest published standards can, at best, confirm for the public what they already believe should be done. Risk communication of exceptional quality from a technical, professional perspective is not necessarily meritorious from a public perspective, but is a hygienic factor that can help maintain the perceived integrity of an organization and its representatives but can do relatively little to improve it.

This model of the relationship between risk management and risk communication is based on research in human judgment that has found that people hold norms and expectations relating to concepts such as honesty and trust, and these norms are powerful determinants of how objects and events are perceived (e.g., Gidron, Koehler, \& Tversky, 1993). Thus, risk communication is perceived by the public in terms of a general process model that includes expectations and theories about how management of societal risks should be carried out. The expectancy theory sets limits on the potential effectiveness of risk communication to foster and promote public trust in risk managers. In addition, it strongly indicates a need to understand how public definitions of risk differ from those of technical experts, and how those definitions lead the public to ask questions of project proponents that are less related to technical issues about risk and more related to project development and management issues that may have little or nothing to do with technical risk assessment.

\section{Public Definitions of Risk}

Risk is one of the oldest concepts in human society, evident by its presence in the Indo-European roots of modern language. The Latin derivation, resecare, is formed from the prefix $r e$, meaning "against" and secare, "to cut." To cut against-to cut off-the part that is cut off or lost: the risk. In one way or another, risk identifies the potential for suffering, harm or loss, and signals danger and uncertainty. For 
contemporary risk analysts, technical definitions of risk are comprised of essentially two components: a potential loss or consequence and a probability or likelihood that the loss would occur. This definition of risk provides a convenient two-parameter framework for analyzing hazards and making explicit the relative advantages and disadvantages of various project designs and means of reducing risk.

For the public, however, risk is defined in terms of factors that relate both to a quantitative and technical definition of risk as well as to the social and psychological context within which technologies, their risks and their benefits are experienced. One framework for conceptualizing a public definition of risk, the psychometric paradigm, has grown out of work which uses psychophysical scaling and multivariate analysis techniques to produce representations or cognitive maps of risk attitudes and perceptions. A second, and more recent, approach is based on advances in cognitive psychology that focus more directly on the content of risk perceptions and attempt to develop comparative mental models of expert and public risk perception.

The Psychometric Paradigm of Risk Perception
The psychometric paradigm (Fischhoff, Slovic, Lichtenstein, Read, \& Combs, 1978; Slovic, Fischhoff, \& Lichtenstein, 1984) has been used to characterize societal risks in general as well as to identify perceptions of risks in specific contexts such as automobile safety (MacGregor \& Slovic, 1989; Slovic, MacGregor, \& Kraus, 1987). Psychometric analyses of risk are typically done by asking respondents, generally members of the public or of some specific group of interest, to evaluate a number of different technologies, activities, or substances in terms of characteristics that relate to the social context of risk, dreadedness of consequences, catastrophic nature of consequences, equitability of risk/benefit distributions, and need for regulation. The resulting judgments are then used to develop a characterization of the set of risks in terms of two general, independent factors comprised of the larger set of judgment scales. Figure 1 is an example of a psychometric analysis done on 81 hazards (Slovic, 1987).

Results like those shown in Figure 1 are generally taken as evidence of why some risks, such as nuclear risks and chemical risks, draw much more concern from the public (or a different kind of concern) than 

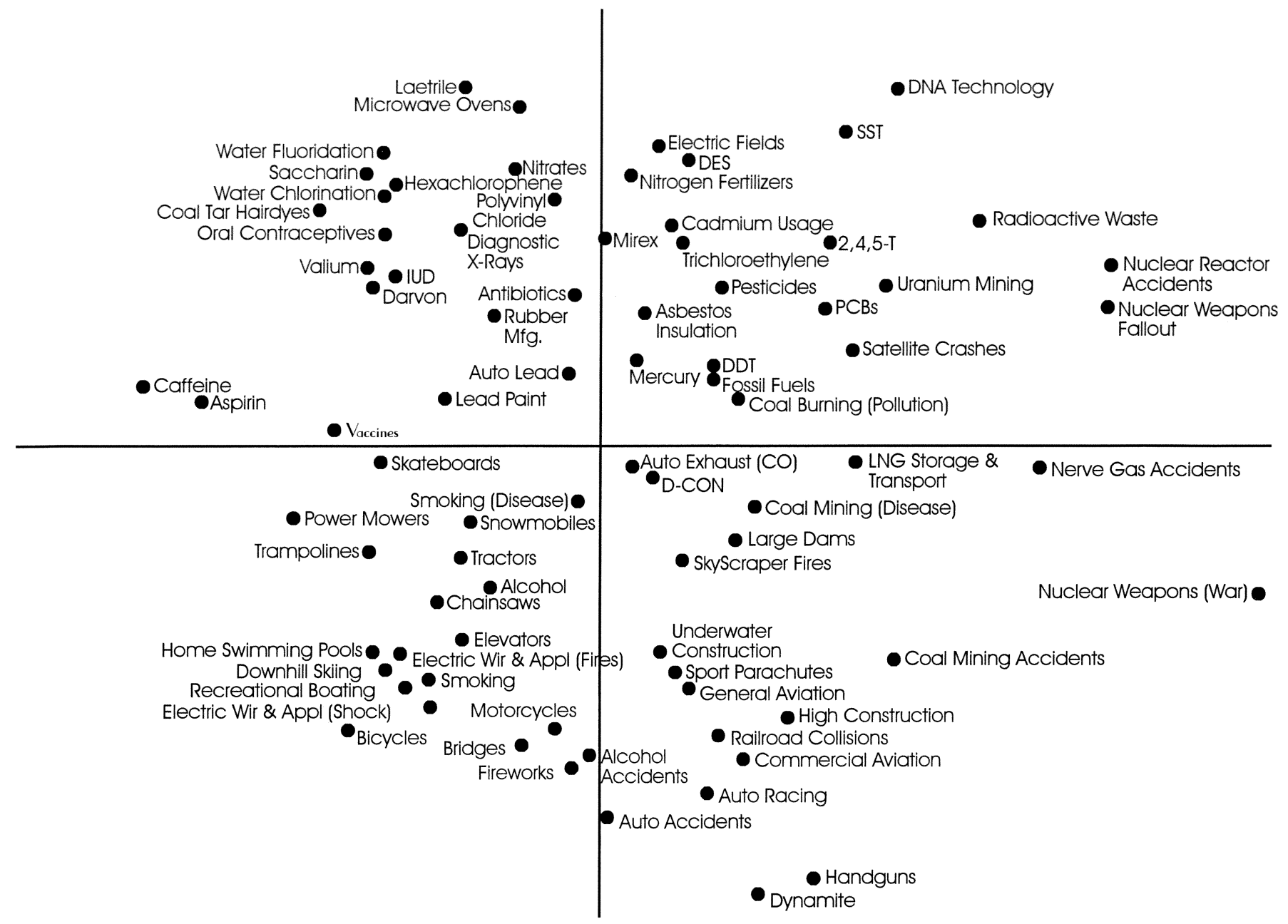

Controllable

Not Dread

Not Global Catastrophic

Consequences Not Fatal

Equitable

Individual

Low Risk to Future Generations

Easily Reduced

Risk Decreasing

voluntary

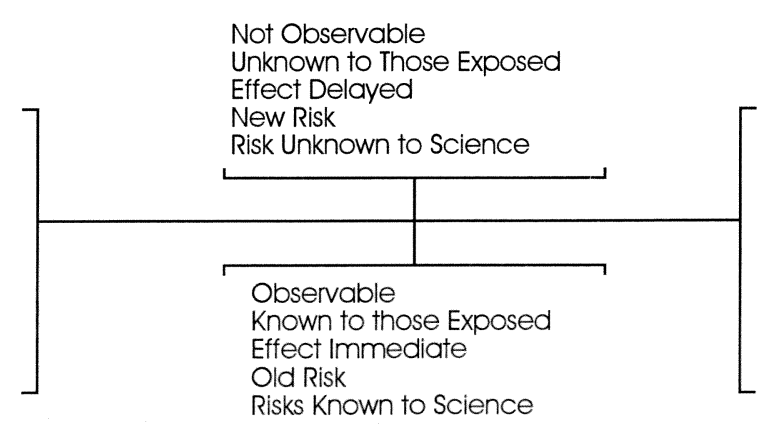

Not Observable

Unknown to Those Exposed

Risks Known to Science

Uncontrollable
Dread
Global Catastrophic
Consequences Fatal
Not Equitable
Catastrophic
High Risk to Future Generations
Not Easily Reduced
Risk Increasing
Involuntary

Factor 2

\section{Factor 1}

Figure 1. Location of 81 hazards on Factors 1 and 2 derived from the interrelationships among 15 risk characteristics. Each factor is made up of a combination of characteristics, as indicated by the lower diagram. Source: redrawn from Slovic (1987). 
would appear to be due given the results of technical analyses. Extreme concerns are generally expressed by the public for risks that fall in the upper right hand quadrant of Figure 1 -these are risks that are generally seen as uncontrollable, dreaded, catastrophic, involuntary, inequitable, and not readily observable. These risks are also ones for which the public overestimates the number of fatalities and expresses a greater desire for regulation.

There are lessons for project proponents that can be gleaned from results like those presented in Figure 1. First, public perceptions of risk are based on two general factors that can be thought of as comprised of subordinate characteristics, most of which are fundamental evaluations that people apply to other life events and contexts, and to which people are highly sensitive, such as the loss of control, involuntariness, catastrophic events, and unfairly bearing risks for which someone else receives the benefits. Even technical risk experts, when evaluating risks outside of their area of technical expertise, are sensitive to these concerns, and may be similar to the public in how they respond to risks with which they have relatively little familiarity. Second, social context dominates quantitative risk assessments as a basis for public assessments of risk. Therefore, risk communication that focuses heavily on technical information is somewhat unlikely to have a broad, positive influence on public attitudes, unless it answers specific questions about how contextual concerns can be managed, such as improving controllability of exposure or addressing inequities in risk/benefit distributions. Finally, it is critical for project proponents to recognize that most members of the public attempt, in one way or another, to comprehend the complexities of a technological project, given their base of knowledge and understanding, as well as their experience with other technologies. Unlike technical experts who have intellectual and technical tools at their disposal, the public for the most part must use simplifying mental strategies to manage what would otherwise be an unassailable task. conceptualizing the social contextual elements that influence risk perceptions, it provides a less detailed picture of how people reason about specific risks and how new information about a given risk will be integrated into what they already know or perceive. A more recent 
strand of research that has evolved along these lines has sought to improve our understanding of the mental models that people use to reason and make inferences about risks. A mental model is a construct used to explain the system of knowledge, attitudes, and beliefs people hold about a particular domain and that they use to answer questions, explain events, or make predictions (e.g., Gentner \& Stevens, 1983; Johnson-Laird, 1983; Johnson-Laird \& Byrne, 1991). In essence, mental model research as applied to risk perception compares the cognitions people hold about a risk with the models of technical experts. For example, Maharik \& Fischhoff (1992) used a mental model approach to contrast expert and lay activist perceptions of the risks and benefits of using nuclear energy sources in space, such as to power interplanetary space vehicles. They found that the activist model of nuclear risk contained many of the same concepts as that of experts, but the concepts were poorly (or not) integrated into an overarching process model of how failure of an aerospace system leads to individual radiation exposure and health effects. Many of the concepts in the expert model were simply absent from the lay model. Significantly, the lay model did not include mention of any benefits of nuclear power in space (though people were directly asked the question), and none of the lay subjects stated explicitly that nuclear energy was the only way to accomplish extended, deep space missions.

MacGregor, Slovic, \& Morgan (in press) used the mental model and psychometric paradigms to evaluate a set of specific risk communication materials developed to inform the public about the potential health risks of exposure to power-frequency electromagnetic fields (EMF). The risk communication materials were in the form of a 16-page brochure, titled Electric and Magnetic Fields from $60 \mathrm{~Hz}$ Electric Power: Briefly, What Do We Know About Possible Health Risks?, developed at Carnegie Melon University under the sponsorship of the Electric Power Research Institute. The brochure was adapted from a larger booklet-over 100,000 copies of the booklet were distributed to interested individuals, other researchers, and various organizations in the electric power industry, including utilities. The content of the booklet has come to form the information kernel of the public information programs on EMF health risks of many local utilities. The brochure was developed as a general introduction to EMF and its potential health risks, with an orientation toward the science of EMF health risks research. As such, it is an over-the-shoulder look at the scientific evidence on EMF health effects, including considerable 
discussion of the scientific uncertainty surrounding existing research. As part of this discussion, the text mentioned appliances and electrical devices found in the home or office. X-rays and microwaves are compared and contrasted with EMF as sources of radiation, and the effects of radiation on DNA and cell tissues are discussed. In its review of research on health effects, various biological mechanisms and health disorders are mentioned, including heart rate, reaction time, brain cancer, birth defects, chronic depression, and neurological disorders. Thus, the risk communication brochure presented a technical and scientific look at a particular health and safety risk.

The results of the evaluation showed that lay people reading the brochure were highly sensitized to a range of potential health effects of EMF, even though the brochure explicitly stated that there was no evidence that EMFs had such an effect (e.g., chronic depression). The model that subjects appeared to use to integrate the information in the brochure was based on the notion of interference; whereby EMFs were seen as interfering with the natural electrical activity of the body much in the same way as a light dimmer might interfere with a radio or cordless telephone. The interference model provided subjects a powerful framework within which to reason about a whole range of health effects for which specific causes are unknown, but could conveniently be inferred from the basic principles of the model (e.g., mental disorders, cancer, heart attacks). Though the brochure was careful to point out that no firm conclusions can be drawn at this time about the effects of EMFs on human health and that scientists do not know of the mechanism relating EMF exposure to health anomalies, lay people appear to have a model of their own that they regard as a powerful and useful tool.

Though only a handful of studies presently exist that have explored the potential of the mental model paradigm in understanding more about risk perception and communication, it is clear that focused work along these lines can yield insights into how risk communication can be improved. If the factual elements of people's mental models are in error, they can be addressed directly by information. If people lack an overarching understanding of how risks evolve, they can be given more understanding of process. If benefits are absent from their mental models, then more balanced communication can be developed. If their mental models lead them to ask questions, then risk communication can move away from information-based strategies and more toward 
processes that put them in closer, direct contact with project proponents.

Worldviews Guide Interpretation of Complex Information
Despite the best efforts of risk communicators to employ techniques that aim to simplify a complex information field, the meaning that people derive from risk communication will often be influenced by strategies that they use to simplify what they have been told.

A powerful simplifying strategy that plays an important role in risk perception comes from work on worldviews. Worldviews are general attitudes or beliefs that predispose people toward different outlooks and have an influence over their judgments about complex risk issues (Buss, Craik, \& Dake, 1986; Cotgrove, 1982; Dake, 1991; Jasper, 1990). Dake (1991) has conceptualized worldviews as "orienting dispositions" because of their role in guiding people's responses in complex situations. Some of the worldviews identified to date are listed below, along with representative attitude statements:

- Fatalism (e.g., "I feel I have very little control over risks to my health")

- Hierarchy (e.g., "Decisions about health risks should be left to the experts")

- Individualism (e.g., "In a fair system, people with more ability should earn more")

- Egalitarianism (e.g., "If people were treated more equally, we would have fewer problems")

- Technological enthusiasm (e.g., "A high technology society is important for improving our health and social well-being")

- Cornucopian (e.g., "The earth is abundant and robust")

- Catastrophist (e.g., "The earth is limited and fragile")

So powerful are worldviews for helping people manage an otherwise complex environment, that even expert judgment is influenced by them. For example, Slovic, Malmfors, and Neil (1993) found evidence that some worldviews are predictive of toxicologists' scientific judgments concerning the carcinogenicity of a chemical tested in a number of animal studies. A group of 125 members of the European Society of Toxicologists completed a survey that asked them to respond to a wide 
range of attitudinal items concerning chemical risks, as well as attitudinal statements relating to a number of worldview dimensions. Part of the survey included a summary description of four animal tests conducted using a chemical named only as Chemical B. The summaries for each of the four studies included exposure concentrations, body weights of the animals, survival rates, neoplastic and non-neoplastic effects, and genetic effects (based on in vitro tests). The chemical and test data were real, taken from the files of the National Toxicology Program. Respondents were asked to judge the degree to which the four studies provided evidence of carcinogenic activity in these animals.

These judgments of carcinogenicity were found to be related to scientists' worldviews. For example, the following item assessed attitudes toward economic growth: "Continued economic growth is necessary to improve our quality of life." Toxicologists who disagreed with this item were approximately 12 times more likely to judge that the studies provided evidence for the carcinogenicity of Chemical B than to judge Chemical B as noncarcinogenic (53.3\% vs. $4.4 \%$ ). However, toxicologists who agreed with the item were only slightly more likely to judge the studies as indicating carcinogenicity than not $(31.4 \%$ vs. $21.6 \%)$.

Perceptions of Risk Analysis as a Decision-Making Approach
Project development involves a complex set of processes that generally includes many stages, activities, institutions, and individuals. For example, consider the management of risks from carcinogenic or toxic chemicals. The magnitude and the probability of the risk is determined by a quantitative risk assessment, a process that itself contains many subanalyses including determination of a dose-response relationship and pathways by which exposure occurs. Regulatory agencies are involved in setting standards about when such chemicals can be used, how they should be transported and stored, how workers should be protected, and what should be done with chemical wastes. Industries are involved in ensuring that regulatory standards are met, that the chemicals are not used unwisely, and that accidents do not occur.

However, the public typically receives little more than a glimpse of how risk analysis and management is actually carried out. For the most part (and for most technological risks) risk management occurs outside 
of the scope of public view. While the public is exposed to events involving technological hazards both directly and through the media, these experiences contain little or no information about the processes by which risks are managed. Indeed, from the public's perspective, risk management is very much a matter of implied trust.

How are risk management processes perceived by the public in terms of their adequacy, acceptability, and trustworthiness? To date, we have little empirical work that directly addresses this question. One study we do have, however, comes from MacGregor and Slovic (1986). They studied lay perceptions of risk assessment applied in the context of risk management decision making. The context for their study was a proposed safety improvement of two different consumer products: motor vehicles and pharmaceutical drugs. Subjects were given one of four different risk assessments used by a manufacturer to decide whether to make a change that would improve safety. One method was based on cost-benefit analysis, and specifically calculated the dollar value of lives lost if product safety was not improved. Two methods were based on risk analysis, one version indicating the numbers of lives lost without safety improvement, and a second version indicating the change in probability of mortality for a single individual. A final version provided a brief description of standard practices for managing this particular risk in the industry, without a quantitative analysis. Each method was evaluated on a set of scales relating to understandability, completeness, logic of reasoning, sensitivity to those effected by the decision, moral and ethical considerations, and a judgment of overall acceptability of the risk management approach. The scales and their wording are shown in Table 1.

The results indicated that the acceptability of risk assessment was related to two general, independent factors. One factor was "logical soundness" where methods that were understandable, logical, and handle uncertainties well were judged more acceptable. The second was a "sensitivity" factor where methods that were sensitive to those affected by risk management and that incorporated moral and ethical considerations were deemed more acceptable. While the analytic approaches tended to score relatively high on the logical soundness dimension, they faired less well on the sensitivity dimension.

The MacGregor and Slovic results suggest that at least two broad dimensions are of importance to lay people in their perceptions of at 
Table 1. Judgment Scales for Risk Assessment Methods
Understanding How well do you feel you understand the method as presented?

Completeness How complete to you feel the method was; to what extent did it consider the factors you feel relevant?

Logic and To what extent does the reasoning in the method seem logically reasoning sound?

Uncertainties To what extent does the method seem to take into account uncertainties about values, information, and consequences?

Expedience To what extent does the method seem to require effort on the part of the decision maker?

Sensitivity To what extent does the method seem sensitive to the wishes of the individuals affected by the decision?

Moral and ethical To what extent does the method consider what is right and wrong considerations from a moral standpoint?

Acceptability To what extent does the method of making a decision seem generally acceptable to you?

Appropriateness How appropriate did the method of making a decision seem in this case?

least some aspects of risk assessment. One dimension is comprised of perceptions of the logic, completeness, understandability, and apparent amount of effort that goes into risk analysis. The second dimension is comprised of judgments about humaneness, the degree to which ethical and moral considerations are addressed, and risk analysis is sensitive to the people exposed to risks. 


\section{The Role of Benefit Assessments in Technological Perceptions}

One of the principal reasons that risk communication is so difficult is that it is about risk. Risk is not an inherently pleasing topic for people. It evokes a great range of concerns and fears, few of which are dampened by more information.

The focus on risk communication is, in many ways, a misplaced focus if the goal is to communicate about a project or a technology. All technologies provide some form of benefit, even if that benefit is the reduction of a pre-existing risk. This fact is so fundamental that it is often overlooked by project proponents, many of whom spend a great deal of time and effort preparing polished portrayals of risk without recognizing that their project was originally intended to provide a benefit.

Research has shown that there is an inverse relationship between risks and benefits-when risks are judged to be relatively high, benefits are judged to be relatively low (Alhakami \& Slovic, in press; Gregory \& Mendelsohn, 1993; Slovic, Kraus, Lappe, Letzel \& Malmfors, 1989; Fischhoff, Slovic, Lichtenstein, Read, \& Combs, 1978). Thus, public perceptions of technology are in terms of a net assessment of risks and benefits. Some research has found that judgments of risk acceptability are more strongly related to perceived benefits than to perceived risks (Vleck \& Stallen, 1981).

Though it is not yet clear exactly how benefit and risk perceptions become related to one another, it is clear that they are not assessed independently. This is a significant finding for risk communication, for it suggests that risk communication may, in some circumstances, do a disservice to a project by emphasizing only one element of its character. Arguably, an informed public should be one capable of making reasoned decisions about technology (NRC, 1989); to do so requires making tradeoffs that require an understanding of both what is to be gained and what is to be lost for each alternative.

A useful, and perhaps more realistic, perspective is to adopt a model of technological communication that casts a given project in terms of its intended goals and outcomes as well as the risks associated with each outcome. It is not reasonable to assume that the public will bring to risk communication (either at meetings or when reading materials) their 
knowledge about the benefits of a project under consideration. Indeed, the public may be unaware of many of the benefits associated with some types of projects and technologies, particularly those that have a beneficial impact distributed over a large number of people or over a long period of time.

Conceivably, one of the reasons that the public has become so sensitized to risk issues is because science has evolved a much richer framework for conceptualizing risk than for conceptualizing benefit. For example, while we have a relatively detailed framework for characterizing public perceptions of risk, we have no comparable framework for characterizing benefits. The effort that has gone into risk research has, in effect, framed most societal decisions about technology in terms of risk-related concepts. From this perspective, the public's apparent concerns about risk are only a reflection of how technological decisions have been portrayed to them.

Risk Communication and the Context of Trust
Social relationships of all types, including risk management, rely heavily on trust. Indeed, much of the contentiousness that has been observed in the risk-management arena has been attributed to a climate of distrust that exists between the public, industry, and riskmanagement professionals (e.g., Slovic, 1993; Slovic, Flynn, \& Layman, 1991). Trust has been discussed extensively as an important factor that contributes significantly to risk communication and to the overall success of risk management. These discussions have emphasized two important qualities of trust-its asymmetry and its fragility. Trust is asymmetrical in the sense that it is more easily destroyed than it is created. Events that have a negative impact on trust have a stronger impact than events that have a positive impact on trust. Overcoming the effects of negative events on trust is tremendously difficult, if not impossible. This asymmetry contributes to the fragility of trust. A trusting relationship with the public can be undone by as little as a single instance or event that signals impropriety, mismanagement, or unreliability.

Though project proponents are frequently advised on the importance of trust and to develop trusting relationships with the public, that advice is seldom given substance with concrete recommendations or specific guides to action. More often, trust (or more appropriately, distrust) is 
provided as an explanation for why project proponents have gotten into trouble with the public, or why a given project or technology has failed to achieve broad public support. It may be more useful, therefore, to go somewhat beyond the existing base of research to identify potential steps that can be taken to help maintain whatever level of trust exists between a project proponent and the public with which it is involved.

Effects of Risk Uncertainty on Perceptions of Trust
One of the questions that constantly plagues risk communicators is how to realistically portray a hazard such that a trusting relationship with the public is fostered. Realism has many possible definitions, some based on principles of technical analysis and others based on what lay people can reasonably be expected to comprehend and assimilate. One person's realism is another person's distortion.

From a technical standpoint, risk assessments are seldom, if ever, highly precise. Uncertainties in technical risk assessments abound from multiple sources, including possible pathways and amounts of exposure, low-dose extrapolations from dose-response relationships established at high exposure levels, and uncertainties about the biological mechanisms by which exposure causes harm. This leaves the risk communicator in the (unenviable) position of having to decide on how much uncertainty to introduce into their messages. While risk communicators are frequently advised to tailor their information to the needs and level of interest of their audiences, the specifics of how to do that are often left undefined.

Some professionals and advisory bodies have suggested that a range of uncertainties better communicates the realities of risk. For example, the Carnegie Commission on Science, Technology, and Government said in 1993 that "communicating a range of doses provides citizens with a more realistic description of a hazard and hence results in more informed choices when the range of risks to which one is exposed is considered" (Risk and the environment, 1993, p. 87). However, audiences often want answers to questions that are different from those that technical analysis is prepared to address. Most imperative among these is whether something is safe. In this light, the introduction of uncertainty into risk communications may serve to confuse an audience or suggest that risk management is somehow deficient or incompetent. 
Evidence of such an effect comes from a recent study by Johnson and Slovic (1994). They studied perceptions of environmental health risks presented to lay respondents as newspaper vignettes. The vignettes described a report from the U.S. EPA on the possibility of cancer risks to a community from one of two sources, either a toxic chemical in the water supply or a naturally occurring radioactive gas. Within the vignettes, technical estimates of risk were varied as to degree of uncertainty by presenting them as either point values or as ranges. Johnson and Slovic found that while people's perceptions of risk were influenced by formative properties of risk communication (i.e., point values versus ranges; numeric vs. graphic presentations), other factors associated with perceptions of agency trustworthiness, honesty, and competence played a much more significant role. Furthermore, when technical risks were presented with greater uncertainty (as a range of estimates), an increase in the perceived honesty of the agency was accompanied by a decrease in their perceived competence.

Results such as these offer a mixed bag. In part, they validate the body of research in risk communication that affirms its effectiveness by finding that people's perceptions of risk are sensitive to variations in the form and content of risk communication. However, risk communication that also conveys technical uncertainty interacts with perceptions of the competence and trustworthiness of risk management. It is not unreasonable to conclude that when a risk management institution is distrusted, increasing the depth of technical communication by, for example, introducing greater uncertainty into technical risk estimates will only serve to make matters worse. In these circumstances, risk communicators may be wise to retreat from pushing their message along technical lines, and direct their efforts instead at improving the public's confidence in the ability of their institutions to perform competent and trustworthy risk management.

Trust and Personalized Risk Communication
Risk communication has come to encompass such a broad range of methods and goals that it can, in principle, subsume everything from the simplest of product warnings to highly individualized contacts with key activists in a potential host community for a project. Trust, as a property of public perceptions of technology, is a quality of human relationships, either between individual representatives of a proposed project and members of a community, or between the public at large 
and an institution. A critical characteristic of distrust is that, once initiated, it tends to inhibit the kinds of personal contacts and experience that are necessary to overcome distrust. In a climate of distrust, it is sometimes perceived by a project proponent as easier to rely on forms of risk communication that doesn't involve the tough, face-to-face contact with the public that often draws criticism and raises emotional energies to uncomfortable levels.

There are several ways that risk communication can become impersonalized. One way is through the overuse of printed matter, particularly when no author or named individual who can be contacted is given. While there are many circumstances in which brochures, booklets, and the like are appropriate and suitable, they should never be a substitute for direct contact between the public and a project proponent. Indeed, even for highly trusted professions, such as medical doctors, people's trust is much higher for their personal physician (whom they know) than for medical professionals in general, or for hospitals. The importance of a named, responsible, and accountable individual as the proponent of a project cannot be overstated. Diffusion of responsibility for a project from individuals to an institution at large can work against establishing a trusting relationship with the public.

\section{The Role of Process in Perceptions of Risk and Risk Management}

Though noone has yet provided a solid prescription for trouble-free project siting, the Yucca Mountain project and others like it that have become stalled in the heat of public contentiousness have led to the development of recommendations that may be helpful in avoiding some future problems. Virtually all of them involve, in one way or another, the creation of a highly participatory environment in which the public is empowered to exercise a role similar (or the same) to that available to them by virtue of the democratic institutions that characterize modern western societies, including a clear mandate for project sitings to be undertaken on a voluntary basis (e.g., Flynn, Kasperson, Kunreuther, \& Slovic, 1992; Slovic, 1993).

Public empowerment in risk management decisions poses strong challenges to risk communication, largely because the process of communication shifts from a didactic, one-way process to a shared process in which the form of a project may change in light of public 
values. The "enlightened" risk communicator, therefore, needs to be aware of how public values about technology are framed, their perceptions of institutional credibility and trust, the agendas of differing publics that motivate their participation in risk debates, and the uncertainties that surround the effectiveness of different participation processes (Kasperson, 1986).

The need for effective participatory strategies has led to guidelines such as the Facility Siting Credo, a framework for facility siting that was developed during a National Facility Siting Workshop in 1990. The Credo makes a distinction between a set of procedural steps that help create a participatory environment conducive to the development of trust and consensus building, and a set of desired outcomes that identify the goal states the procedures should be directed toward (Kunreuther, Fitzgerald, \& Aarts, 1993). Table 2 summarizes the principal elements of the Credo.

An evaluation of the effectiveness of the Credo was done by surveying 29 waste facility siting cases, both successful and unsuccessful, across

Table 2. Principal Elements of the Credo

\section{Procedural steps}

- Institute a broad-based participatory process

- Seek consensus

- Work to develop trust

- Seek acceptable sites through a volunteer process

- Consider a competitive siting process

- Set realistic timetables

- Keep multiple options open at all times

Desired outcomes

- Achieve agreement that the status quo is unacceptable

- Choose the solution that best addresses the problem

- Guarantee that stringent safety standards will be met

- Fully address all negative aspects of the facility

- Make the host community better off

- Use contingent agreements

- Work for geographic fairness 
the United States and Canada. The results revealed that successful sitings tended to be those in which an atmosphere of trust was achieved between the proponent and the host community, and the proposed facility was seen by the community as appropriate and meeting its needs (Kunreuther, Fitzgerald, \& Aarts, 1993). However, it remains to be seen how well the Credo fares in other siting contexts other than noxious wastes. Many of the sitings studied by Kunreuther et al. were for projects having high benefit to a local community, such as a municipal land fill. Arguably, these projects are more easily justified to community members because the benefits are almost exclusively distributed locally. On the other hand, projects such as dams and power generation facilities (e.g., natural gas cogeneration) fill much larger needs that those of a local community, and a significant disparity exists between their risk and benefit distributions.

Nonetheless, the Credo points the way to the direction that project proponents and risk managers need to take if their goal is to achieve some measure of public contentment with how facilities are sited. It is fair to conclude that the future of facility siting and risk management will involve a greater degree of public participation than it has in the past. In all likelihood, that involvement cannot come too early in the project development cycle, even to the extent of guiding technical decisions about how a facility will be designed and constructed. increasing set of challenges to fostering good relationships with the public. Without a doubt, risk communication will continue to play a vital and central role in risk management, if for no other reason than people will always want to know something about "the facts" of the risks to which they are exposed. Technical risk assessment is, for the foreseeable future, the means by which those facts become known to science. The state of that science for any given hazard will always be of interest to the public, and to one of its principal messengers, the media.

But, risk communication is no magic bullet. It is but a relatively small part of a larger social process by which risks are decided on and managed, and by which technologies come to be either rejected or accepted. The following conclusions and caveats may be of help in gauging what risk communication can reasonably accomplish, and 
where else one's energies might be expended more productively.

Recommendations for Alternative Risk

Communication and Management Processes
- Higher quality public involvement. The research clearly shows that public involvement is a necessary part of risk management. However, the research is less clear on the specifics of what that involvement should look like. Though some researchers recommend greater public involvement in risk management decisions, it is less certain that more is necessarily better. It is perhaps more appropriate to conclude that public involvement of high quality is more important than, for example, involving more members of the public, or involving the public more deeply in issues that they are poorly prepared to grasp. There is a risk in taking the tack of involving the public by allowing them to cathart and express their anger and rage, but doing very little to accommodate their views or change how things are done. This form of involvement is perhaps better characterized as indulging the public, which sometimes happens under the guises of involving the public more.

High quality public involvement has not yet been well defined. Risk management institutions must develop guidelines for high quality public involvement. These guidelines should be based on definitions of what is wanted from the public, and how their viewpoints will be incorporated into risk management decisions. Are there technical decisions where public values would be relevant? Can the public be helpful in defining approaches for relating to their own constituency? Is there training and education that the public needs to be an active, valued, and respected participant in risk management?

- Earlier involvement of the public in the project development cycle. Very often, the difficulties that project proponents face in the public arena are brought about because those impacted by a project are the last to know of its existence. Project development is a complex and risky process. For project developers, the road that leads from an idea to a construction permit is a long and hazardous one. Only a very small number of the projects that are considered actually make it to the point of filing an application with a regulatory agency. Usually by the time an application is filed, many decisions have been made that are very difficult to reverse, making it virtually impossible for a proponent to 
incorporate the public's input. Project proponents need better advice on how to involve the public earlier in the development cycle. And, risk management institutions need better guidance on how they can give that advice in a responsible way that is sensitive both to the needs of the public and to the constraints and problems faced by the proponents.

- Greater reliance on volunteer communities. For the public to be a willing partner in technology, it needs to know what is in it for them. For a project to be of true benefit to a community, it must fit within their own framework of goals and objectives, and not just those of project developers. Project proponents should be encouraged to strive for a partnership with host communities. The first step in establishing that partnership is a recognition of the critical importance of voluntariness in decisions about technology. The normal project development process can seem to community members as imposing the results of decisions made by others on them, particularly when public involvement does not occur until far downstream from project planning. By working toward voluntary participation in project development, proponents may actually reduce the risks that a project will run into trouble that can result in costly delays or even more costly abandonment.

- Increase public trust in risk management or develop processes that don't rely on trust. We are currently at an important junction in the evolution of socially accountable risk management. All the research to date on the failures of risk management point strongly to the erosion of trust both in government and in many of our social institutions as an important causal factor in the conflicts that exist between the community of risk experts and the public. At this juncture, we need to move forward in one of two directions. One path that has been advocated is to work toward increasing public trust in risk management. The previous sections discussed research that has been conducted in this spirit. While it is much too soon to express either optimism or pessimism about the likely success of this strategy, it is a significantly challenging problem that at the moment appears to have no easy answers.

A second path leads in the direction of developing risk management 
processes that don't rely on trust, or rely on it only minimally. Though it is seldom acknowledged explicitly, many of the steps currently being taken by government and industry to involve the public through community advisory panels and the like are, in effect, establishing layers of oversight such that the checks-and-balances principles inherent in democratic governments are instituted within technological risk management. This may be a fruitful avenue to pursue, and research along these lines is certainly needed.

- Increased accountability of the public for their role in risk management. Ideally, the public and risk professionals would work with each other in a climate of mutual respect. One conclusion that can be drawn from the body of social science research that has identified some of the sources of public discontent is that the public holds a viewpoint that mimics the complaint of Rodney Dangerfield, "I don't get no respect." However, respect is a two-way street and doesn't come without a demonstration of one's worthiness. If the public wants greater respect from technical experts and risk managers, they will need to develop a greater awareness of accountability for their role in risk management. While risk management professionals are accountable to their institutions, the public, their profession, and the legal system for their actions, the public has no such oversight. For example, intervenors in a siting process can inject into proceedings whatever facts and opinions they choose without having to account for their accuracy or their possible negative impacts. If risk management professionals evidence disdain for the public in some circumstances, perhaps it is because the public sometimes takes on a herd mentality, expressing opinions as facts and exhibiting a tyranny of the masses.

The public needs more education in risk issues. Not so they will understand the technical facts and accept them uncritically, but so that their criticisms will be from a place of understanding that which they are criticizing. Developers and project proponents have respect for members of the public who do take the time to become knowledgeable in the depth and breadth of the problems at hand. However, many members of the public reduce societal decisions to the minuscule and self-absorbed confines of their own lives. It is not simply up to risk management professionals to learn the ways of the public. The public must also learn about the individuals and institutions which the democratic process has established to manage risks on behalf of 
society. There is an imbalance of awareness. Risk managers are implored to be aware of and sensitive to the views of the public, but the public is not implored to learn about technology, its benefits, its risks, and the problems of managing them. In attempting to accommodate the public, we often accommodate all of the public without discriminating well between those whose viewpoints and values are evolved and welldeliberated, and those who have invested relatively little time and effort into becoming risk literate.

To these ends, public education about risk assessment and risk management is imperative. Certainly the current national emphasis in education on developing greater public awareness and literacy in science is laudable and of great benefit. However, general knowledge of science is not enough. Informed viewpoints on risk issues require an appreciation of the complexities of risk assessment and some fluency in interpreting the results of multiple, and often conflicting, scientific studies. Furthermore, no technology is simply its risks. Most technologies that come under public scrutiny provide benefits. Many times, those benefits are actually an alleviation of a risk that existed before the technology was developed. Thus, many societal decisions about risk that are framed as a risk/benefit tradeoff are actually a risk/risk evaluation. However, the risks of life before many of our current technologies existed is only comprehensible by taking a close look at the basic needs that a technology fulfills. If risk managers sometimes appear not to appreciate the public's attitudes about risk it is perhaps because the public often trivializes the benefits of technology by assuming its existence, and excluding the risks to which they would be exposed without it.

- A goal of risk communication should be to facilitate movement toward a negotiating position. Project proponents who are successful in today's social arena generally are those who recognize the powerful role that public opinino plays in technological development. Though in previous decades technological development generally moved forward without broad-based public involvement, that is less so today and is very likely to be even less so in the future. Risk communication can be an effective tool for advancing technological development if it is pursued with the intention of reaching a position whereby a project proponent and a potential host community or partner can enter into a negotiation around a given project that advances the goals and objectives of both parties. 
With virtual certainty, attempting to ignore the risks of a technological project will not facilitate achieving that goal. Likewise. entering into a debate with the public about whose definition of risk is the appropriate or "correct" one will only direct the dialogue away from a consideration of a project's full range of impact, including those that are to benefit. The answers lie in acknowledging a project's risks and representing those risks as fairly as possible in terms that both parties can comprehend and agree on. Approached in this spirit, risk communication can play a role in a negotiated settlement about the suitability of a given project for a particular community, or can be helpful in technical or engineering modifications that are based on a reasoned consideration of risks. 
Alhakami, A.S., \& Slovic, P. (in press). A psychological study of the inverse relationship between perceived risk and perceived benefit. Risk Analysis.

Buss, D. M., Craik, K. H., \& Dake, K. M. (1986). Contemporary worldviews and perception of the technological system. In V. T. Covello, J. Menkes, \& J. Mumpower (Eds.), Risk evaluation and management (pp. 93-130). New York: Plenum.

Cotgrove, S. (1982). Catastrophe or cornucopia: The environment, politics and the future. New York: Wiley.

Covello, V. T., Sandman, P. M., \& Slovic, P. (1988). Risk communication, risk statistics, and risk comparisons: A manual for plant managers. Washington, DC: Chemical Manufacturers Association.

Covello, V. T., von Winterfeldt, D., \& Slovic, P. (1986). Risk communication: A review of the literature. Risk Abstracts, 3, 171-182.

Dake, K. (1991). Orienting dispositions in the perception of risk: An analysis of contemporary worldviews and cultural biases. Journal of Cross-Cultural Psychology, 22, 61-82.

Fischhoff, B., Slovic, P., Lichtenstein, S., Read, S., \& Combs, B. (1978). How safe is safe enough? A psychometric study of attitudes towards technological risks and benefits. Policy Sciences, 9, 127-152.

Flynn, J., Kasperson, R., Kunreuther, H., \& Slovic, P. (1992, Summer). Time to rethink nuclear waste storage. Issues in Science and Technology, pp. 42-48.

Gentner, D., \& Stevens, A.L. (1983). Mental models. Hillsdale, NJ: Lawrence Erlbaum.

Gidron, D., Koehler, D. J., \& Tversky, A. (1993). Implicit quantification of personality traits. Personality and Social Psychology Bulletin, 19, 594-604.

Gregory, R., \& Mendelsohn, R. (1993). Perceived risk, dread, and benefits. Risk Analysis, 13, 259-264.

Jasper, J. M. (1990). Nuclear politics: Energy and the state in the United States, Sweden, and France. Princeton, NJ: Princeton University Press. 
Johnson, B. B., \& Slovic, P. (1994). Explaining uncertainty in health risk assessment: Effects on risk perception and trust (Report No. 94-3). Eugene, OR: Decision Research.

Johnson-Laird, P.N. (1983). Mental models. Cambridge, MA: Harvard University Press.

Johnson-Laird, P.N., \& Byrne, R.M.J. (1991). Deduction. Hillsdale, NJ: Lawrence Erlbaum.

Kasperson, R. E. (1986). Six propositions on public participation and their relevance for risk communication. Risk Analysis, 6, 275-281.

Kunreuther, H., Fitzgerald, K., \& Aarts, T. D. (1993). Siting noxious facilities: A test of the facility siting credo. Risk Analysis, 13, 301-318.

MacGregor, D. (1991). Worry over technological activities and life concerns. Risk Analysis, 11, 315-324.

MacGregor, D., \& Slovic, P. (1986). Perceived acceptance of risk analysis as a decision-making approach. Risk Analysis, 6, 245-256.

MacGregor, D., \& Slovic, P. (1989). Perception of risk in automotive systems. Human Factors, 31, 377-389.

MacGregor, D., Slovic, P., \& Morgan, M.G. (in press). Perception of risks from electromagnetic fields: A psychometric evaluation of a risk-communication approach. Risk Analysis.

Mahavik, M., \& Fischhoff, B. (1992). The risks of using nuclear energy sources in space: Some lay activists' perceptions. Risk Analysis, 12, 383-391.

National Research Council. (1989). Improving risk communication. Washington, DC: National Academy Press.

Risk and the environment. (1993). New York: Carnegie Commission on Science, Technology, and Government.

Singer, E., \& Endreny, P. M. (1993). Reporting on risk. New York: Russell Sage Foundation.

Slovic, P. (1987). Perception of risk. Science, 236, 280-285.

Slovic, P. (1993). Perceived risk, trust, and democracy: A systems perspective. Risk Analysis, 13, 675-682. 
Slovic, P., Fischhoff, B., \& Lichtenstein, S. (1984). Behavioral decision theory perspectives on risk and safety. Acta Psychologica, 56, 183203.

Slovic, P., Flynn, J., \& Layman, M. (1991). Perceived risk, trust, and the politics of nuclear waste. Science, 254, 1603-1607.

Slovic, P., MacGregor, D., \& Kraus, N. (1987). Perception of risk from automobile safety defects. Accident Analysis and Prevention, 19, 359-373.

Slovic, P., Malmfors, T., \& Neil, N. (1993). Toxicologists' judgments of chemical risks: The 1993 Eurotox survey (Report No. 93-12). Eugene, OR: Decision Research.

Slovic, P., Kraus, N., Lappe, H., Letzel, H., \& Malmfors, T. (1989). Risk perception of prescription drugs: Report on a survey in Sweden. Pharmaceutical Medicine, 4, 43-65.

Vleck, C., \& Stallen, P.-J. (1981). Judging risks and benefits in the small and in the large. Organizational Behavior and Human Performance, 28, 235-271. 